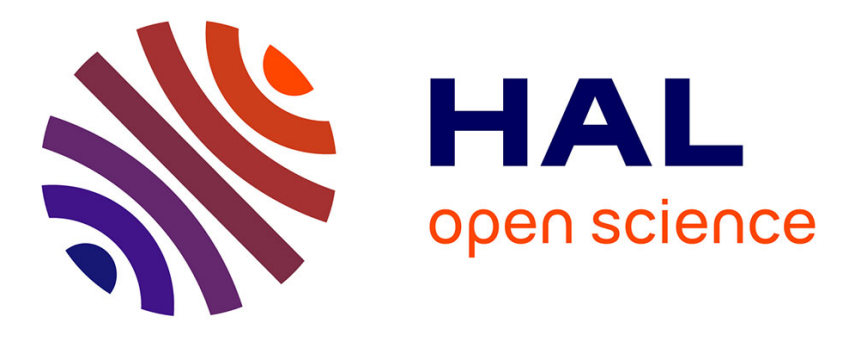

\title{
Fabrication and characterization of Iodine Vapor Photonic Microcell
}

C Goïcoechéa, T Billotte, M Chafer, M Maurel, J Jouin, P Thomas, Frédéric Gérôme, B Debord, F Benabid

\section{To cite this version:}

C Goïcoechéa, T Billotte, M Chafer, M Maurel, J Jouin, et al.. Fabrication and characterization of Iodine Vapor Photonic Microcell. CLEO: Conference on Lasers and Electro-Optics 2021 US, May 2021, San José (virtual), United States. pp.STh1A.3. hal-03285525

\section{HAL Id: hal-03285525 \\ https://hal.science/hal-03285525}

Submitted on 21 Jul 2021

HAL is a multi-disciplinary open access archive for the deposit and dissemination of scientific research documents, whether they are published or not. The documents may come from teaching and research institutions in France or abroad, or from public or private research centers.
L'archive ouverte pluridisciplinaire HAL, est destinée au dépôt et à la diffusion de documents scientifiques de niveau recherche, publiés ou non, émanant des établissements d'enseignement et de recherche français ou étrangers, des laboratoires publics ou privés. 


\title{
Fabrication and characterization of Iodine Vapor Photonic Microcell

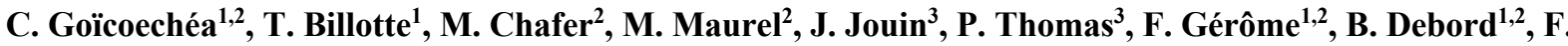 \\ Benabid $^{1,2}$ \\ ${ }^{I}$ GPPMM Group, Xlim research institute, University of Limoges, 123 avenue Albert Thomas 87060 Limoges, FRANCE. \\ ${ }^{2}$ Glophotonics, 123 avenue Albert Thomas 87060 Limoges, FRANCE. \\ ${ }^{3}$ IRCER UMR CNRS 7315, Centre Européen de la Céramique, 12 rue Atlantis, 87068 Limoges, France. \\ f.benabid@xlim.fr
}

\begin{abstract}
A standalone FC/PC connectorized and sealed Iodine filled hollow core fiber with coupling efficiency as high as $75 \%$ and an absorption contrast reaching $65 \%$ on the $\mathrm{P}(33) 6-3$ transition at room temperature is demonstrated. (C) 2020 The Author(s)
\end{abstract}

\section{Introduction}

The dense hyperfine transitions of iodine in the visible spectrum has been of particular interest in a number of applications such as frequency standards for lasers emitting in the visible spectrum, in particular in the range 500$800 \mathrm{~nm}$ [1-3]. As an example of the high frequency stability that could be achieved using iodine ( $\left.\mathrm{I}_{2}\right)$ vapor absorption lines as frequency references is the demonstration of an optical clock with a fractional frequency stability below 4.6 $\times 10^{-13}$ over 1 year integration time [4]. Another application for Iodine absorption cells is the high resolution spectrograph used for probing bright stars where Doppler precision of $4-7 \mathrm{~m} / \mathrm{s}$ has been achieved [5]. However, iodine is very difficult to handle because of its chemical and physical properties. Indeed, it is highly reactive with metal and is in solid phase at room temperatures necessitating to heat or put it under vacuum to transform it in a gas phase. The main drawback today in the use $\mathrm{I}_{2}$ as a frequency standard is the difficulty to integrate the containing cell into optical systems due to its large footprint, the lack of plug \& play connectors and the need to place it in an oven to operate at higher temperature for line so to achieve the required level of contrast and signal-to-noise ratio. The continuous progress in hollow core photonic crystal fiber (HCPCF) enables today to achieve transmission loss below $14 \mathrm{~dB} / \mathrm{km}$ in the visible wavelength range [6]. HCPCF has proven to be an excellent alternative to bulky cells thanks to their capability of confining gases on a micrometer scale on long distances enhancing the interaction between gases and the photons [7]. These sealed fibers loaded with gases are coined photonic micro cells (PMC). This interaction enhancement enables to have strong absorption whilst operating at lower gas density, thus limiting the pressure broadening. Other advantages to mention are the possibility to integrate them to optical systems in a compact and easy way thanks to the connectorisation of the fiber tips. Previous work done with HCPCF filled with $\mathrm{I}_{2}$ has shown the benefits of a reduced footprint and the easiness of overlapping the pump and probe beam [8]. They have also shown some limits such as the broadened linewidth due to a shorter transit time at the same laser intensity and $\mathrm{I}_{2}$ pressure but also due to background gases introduced by the set-up. Another noticeable drawback in the state of the art of sealed HCPCF is the losses due to the sealing (18dB) [9]. Thanks to the sealing technique recently introduced by Billotte et al. [10] the inconvenience of this high loss seal is lifted. In addition, the fiber tips have been put in standard fiber optical connectors of type FC/APC adding to it friendly user use.

Here we report on all-fiber and standalone Iodine PMC. The loading process was achieved using specific gasmanifold that prevents any chemical reaction with $\mathrm{I}_{2}$. The loading process is as short as half a day to fill several meters long $\mathrm{HCPCF}$ with $\mathrm{I}_{2}$ at the target vapor density. The achieved PMC shows a contrast of $65 \%$ compared to $10 \%$ in a macroscopic cell (on the $\mathrm{P}(33)$ 6-3 transition) at room temperature. This contrast is very promising for saturable absorption spectroscopy (SAS) and frequency standard applications. An important feature is the coupling efficiency of the pump achieved in our PMC which reaches $75 \%$. The fiber tips of the PMC have a standarized FC/APC for a friendly user utilization and facilitate the integration to an optical system.

\section{Experimental setup and results}

Figure 1(a) shows the vacuum manifold for loading the HCPCF with iodine molecule and monitoring its optical absorption. The manifold parts have been treated against corrosion and to prevent reaction between the metal and $\mathrm{I}_{2}$ vapor. The manifold consists of several chambers that can be isolated from each other by vacuum valve. The $\mathrm{I}_{2}$ dispenser chamber consist of glass tube that can be pressurized or temperature regulated. The HCPCF tip chamber consists in a vacuum compatible fiber mount and faced to an optical window for laser coupling. A cryogenic trap is placed accordingly to prevent damage of the vacuum pump during the fiber loading period. The process of $\mathrm{I}_{2}$ filling is carried out at room temperature followed a sequence of different steps. First, the HCPCF is flushed with Helium and heated several hours at $110^{\circ} \mathrm{C}$ to get rid of any residual contaminant in the fiber. One end of the HCPCF is endcapped using the method reported in [10] and is mounted on FC/APC connector. A laser beam from 633nm ECD 
Laser (Toptica - DL100/PRO) is coupled through this connector. Here, the other fiber tip is connected through a "sleeve" capillary to a shorter piece of the same fiber batch, which is mounted to the manifold. The latter is vacuum pumped down to a pressure level of $10^{-6} \mathrm{mbar}$, leading thus to vaporization of $\mathrm{I}_{2}$ in the system, and loading in the HCPCF. The HCPCF transmission monitored over a chosen iodine absorption spectral range. Once the desired absorption contrast is reached, the second HCPCF end is then end-capped using the same method as with the first fiber tip. The latter is then mounted into an FC/APC connector to form a seemingly standalone fiber patchcord that is $\mathrm{I}_{2}$ PMC.The fiber chosen to develop the $\mathrm{I}_{2}$ PMC is a $\sim 4 \mathrm{~m}$ long piece of IC HCPCF with tubular lattice and core diameter of $\sim 37 \mu \mathrm{m}$. The fiber presents a transmission window from $570 \mathrm{~nm}$ to $660 \mathrm{~nm}$ with minimum loss of 7.8 $\mathrm{dB} / \mathrm{km}$ at $633 \mathrm{~nm}$ (see Figure 1(b)), covering many of absorption $\mathrm{I}_{2}$ transitions.

(a)

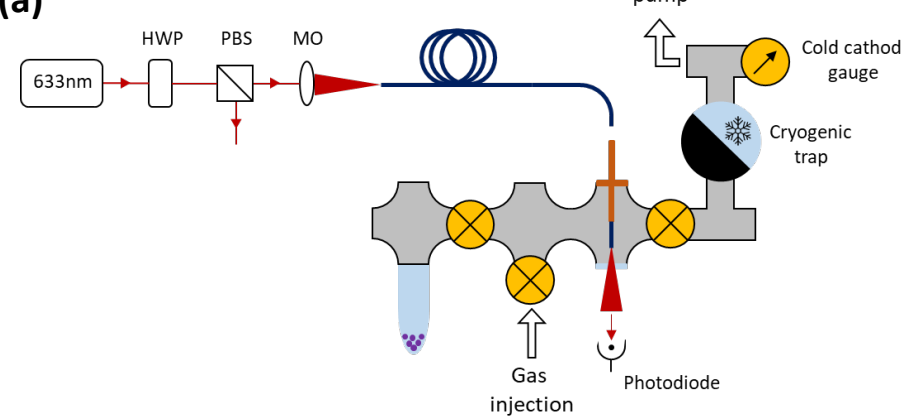

(b)

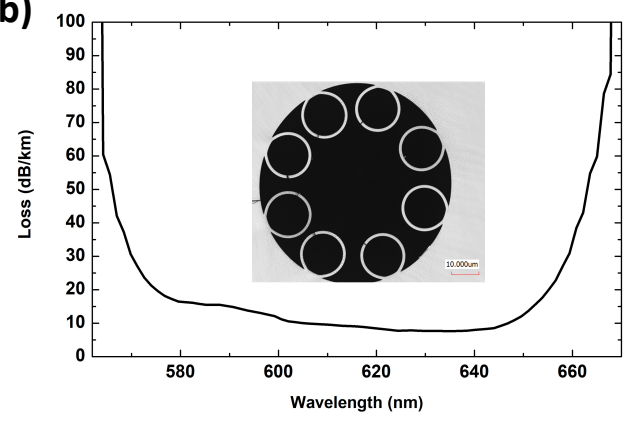

Figure 1. (a) Schematic of the experimental set-up for $I_{2}$ HCPCF filling process. (b) Loss spectrum around $633 \mathrm{~nm}$ spectral range of the experimental HCPCF. In inset: Micrograph of the cross-section of the HCPCF.

The picture of the final developed FC/PC connectorized $\mathrm{I}_{2} \mathrm{PMC}$ is presented in Figure 2(a). The footprint is reduced from a bulky cell to that of an optical fiber. The coupling efficiency of the the PMC reaches $75 \%$ by coupling laser beam to the first connector, more than $16 \mathrm{~dB}$ times larger than the transmission obtained in [9]. Figure 2(b) shows the comparison of the linear absorption spectra recorded at room temperature after transmission of ECDL beam along the PMC (black curve) and along $10 \mathrm{~cm}$ long commercial $\mathrm{I}_{2}$ gas cell. The frequency is given relative to $\mathrm{P}(33) 6-3$ transition. One can notice the strong contrast offered by the PMC with a $65 \%$ value, more than 6 times larger than the one obtained with the commercial gas cell. Future work involves the generation of SAS and laser frequency stabilization.

(a)

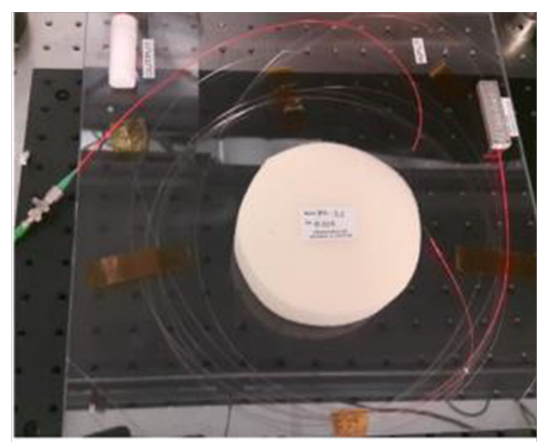

(b)

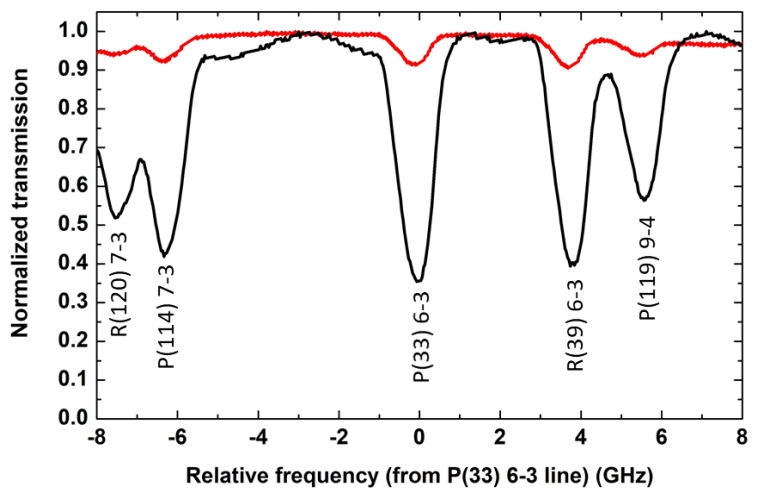

Figure 2. (a) Overall picture of the developped FC/APC connectorized $I_{2}$ PMC. (b) Linear absorption spectrum of I2 through the developed PMC (black curve) and commercial gas cell (red curve).

\section{References}

[1] R. Hamid, et al., Metrologia, 43, 106-108 (2006).

[2] G. D. Rovera, et al., Measurement Science Technology, 13, 918922 (2002).

[3] P. Dubé \& M. Trinczek, J. Opt. Soc. Am. B 21, 1113-1126 (2004).

[4] J. Ye, L.S. Ma \& J.L. Hall, Physical Review Letters, 87(27), 270801-4 (2001).

[5] L. A. Crause, et al., Proceedings V10702, Ground-based and Airborne Instrumentation for Astronomy VII; 107025 S (2018).
[6] Chafer, M. et al., IEEE Photonics Technol. Lett. 31, 685-688 (2019).

[7] F. Benabid, et al., Nature 434, 488 (2005).

[8] A. Lurie, et al., Optics Letters, 36(24), (2011).

[9] P. S. Light, et al., Optics Letters, 40(12), (2015).

[10] T. Billotte, et al., CLEO/Europe-EQEC 2019, OSA, Munich, Germany. Paper CH-P. 17 (2019) 